\title{
Fluorescent AIE-Active Materials for Two-Photon Bioimaging Applications
}

\author{
Qing Lu ${ }^{1}$, Cheng-Juan $\mathrm{Wu}^{2 *}$, Zhiqiang Liu ${ }^{1}$, Guangle Niu ${ }^{1 *}$ and Xiaoqiang $\mathrm{Yu}^{1}$ \\ ${ }^{1}$ State Key Laboratory of Crystal Materials, and Advanced Medical Research Institute, Shandong University, Jinan, China, \\ ${ }^{2}$ College of Chemistry, Chemical Engineering and Material Science, Shandong Normal University, Jinan, China
}

\section{OPEN ACCESS}

Edited by:

Wei Qin,

Sun Yat-sen University, China

Reviewed by:

Kai Li,

Southern University of Science and Technology, China

Peisheng Zhang,

Hunan University of Science and

Technology, China

*Correspondence:

Cheng-Juan Wu

wucj@sdnu.edu.cn

Guangle Niu

niug@@sdu.edu.cn

Specialty section:

This article was submitted to

Analytical Chemistry,

a section of the journal

Frontiers in Chemistry

Received: 14 October 2020 Accepted: 26 November 2020

Published: 14 December 2020

Citation:

LU Q, Wu C-J, Liu Z, Niu G and YuX (2020) Fluorescent AlE-Active Materials for Two-Photon Bioimaging Applications. Front. Chem. 8:617463. doi: 10.3389/fchem.2020.617463
Fluorescence imaging has been widely used as a powerful tool for in situ and real-time visualization of important analytes and biological events in live samples with remarkably high selectivity, sensitivity, and spatial resolution. Compared with one-photon fluorescence imaging, two-photon fluorescence imaging exhibits predominant advantages of minimal photodamage to samples, deep tissue penetration, and outstanding resolution. Recently, the aggregation-induced emission (AIE) materials have become a preferred choice in two-photon fluorescence biological imaging because of its unique bright fluorescence in solid and aggregate states and strong resistance to photobleaching. In this review, we will exclusively summarize the applications of AlE-active materials in two-photon fluorescence imaging with some representative examples from four aspects: fluorescence detection, in vitro cell imaging, ex vivo tissue imaging, and in vivo vascular imaging. In addition, the current challenges and future development directions of AlE-active materials for two-photon bioimaging are briefly discussed.

Keywords: two-photon, aggregation-induced emission, fluorescent material, fluorescent detection, fluorescence imaging

\section{INTRODUCTION}

In recent years, fluorescence imaging has been widely used as a powerful tool for in situ and real-time visualization of important analytes and biological events in live samples with remarkably high selectivity, sensitivity, and spatial resolution (Ding et al., 2018; Zheng et al., 2019; Zhou et al., 2019; Liu et al., 2020; Lv Z. et al., 2020). Most of the structures and components in live samples do not emit fluorescence. Only when the fluorescent material specifically binds to the target, can the target be observed by the fluorescence microscope. Then the imaging and observation of ions, small biological molecules such as amino acids, sugars and cholesterol, biological macromolecules, various organelles, and the intracellular microenvironment at the cellular level are realized. Therefore, the development of fluorescence imaging depends not only on the microscopic technology, but also on the fluorescent materials.

Two-photon fluorescence bioimaging has incomparable advantages over one-photon (Scheme 1): first, it uses near-infrared (NIR) photon as the excitation source and causes mild photondamage to live samples (Looney et al., 2011); second, due to low excitation light scattering and NIR excitation, it can be used for deep penetrating imaging of tissues (Tadayon et al., 2019). Moreover, it emits light only when it is in the focus position in bioimaging, resulting in ultrahigh resolution (Song et al., 2020). Therefore, compared with one-photon fluorescence imaging, it is of great significance to perform two-photon fluorescence imaging to visualize important substances and biological processes in biological systems and reveal the mysteries of life systems (Gao Y.T. et al., 2020; Li Y. et al., 2020; Li Y.Y. et al., 2020; Zheng et al., 2020). 


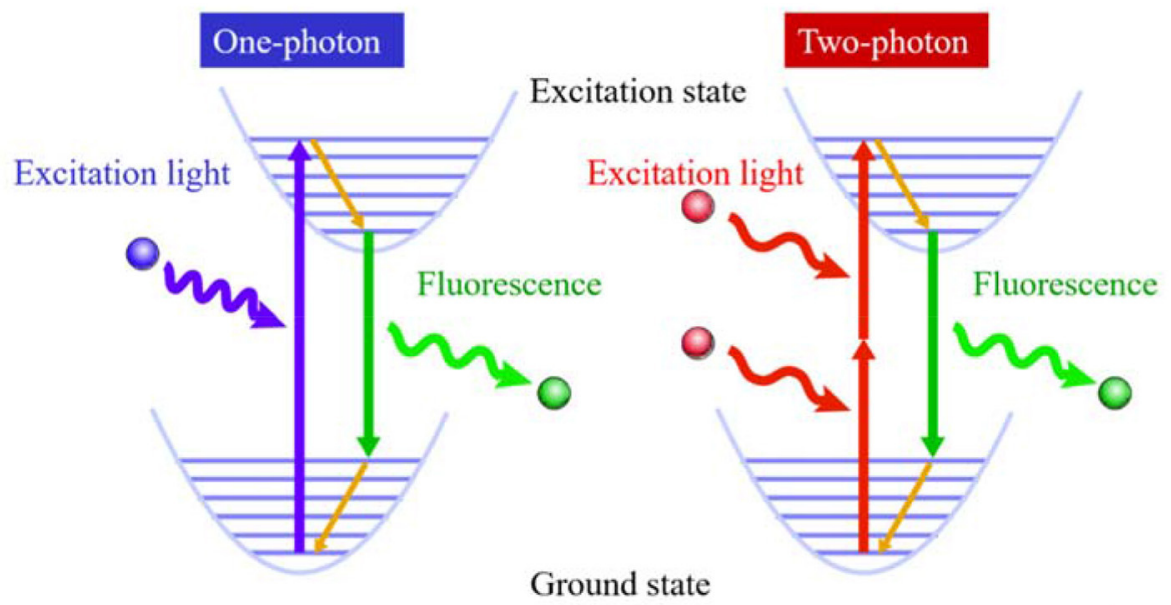

SCHEME 1 | Principle of two-photon excited fluorescence for bioimaging.

However, the laser energy used in two-photon fluorescence imaging is relatively strong, and the photobleaching resistance of most traditional organic fluorescent materials is limited. One method to enhance their anti-photobleaching ability is increasing the concentration of traditional organic fluorescent materials, but they are prone to aggregation at high concentration in biological systems, which causes fluorescence quenching due to strong $\pi-\pi$ stacking (Figure 1A). Another effective method is designing organic fluorescent materials with a large two-photon absorption cross section by introduction of strong electron donor and acceptor groups as well as extending the length of $\pi$-conjugation. As these strategies cause high hydrophobicity, the same problem of fluorescence quenching still exists. Thus, it is of great significance to develop new fluorescent materials to surmount the quenching problem of traditional hydrophobic fluorescent materials at a high concentration in a biological environment.

A new class of fluorescent materials (Figure 1B) with aggregation-induced emission (AIE) discovered by Tang's group and others have received considerable attention due to their unique photophysical properties (Luo et al., 2001; An et al., 2002, 2012; Shimizu et al., 2009; Shustova et al., 2013; Yan et al., 2015; Sasaki et al., 2016; Li and Li, 2017; Tsujimoto et al., 2017; Zhang et al., 2017; Ren et al., 2019; Guo et al., 2020; Hu et al., 2020; Kong et al., 2020; Mao et al., 2020; Qin et al., 2020). The widely accepted working mechanism of AIE-active fluorescent materials is restriction of intramolecular motions (Mei et al., 2015; Chen et al., 2019; Tu et al., 2020), thus the AIE materials generally show strong emission in aggregate and solid states and strong photobleaching resistance (Hong et al., 2011; Chen Y. et al., 2018; Cao et al., 2019; Li et al., 2019; Chen et al., 2020; Feng H. et al., 2020; He et al., 2020b; Huang et al., 2020; Li Q. et al., 2020; Ni et al., 2020; Wei et al., 2020; Xu Y. et al., 2020; Yin et al., 2020). On the other hand, AIE materials mostly exist in the form of nanoaggregates in biological systems, which are not easily discharged by the biological system through metabolism, enabling long-term dynamic tracking (Xie et al., 2019; Niu et al., 2020).

In a word, AIE materials are an ideal choice for two-photon fluorescence imaging. Recently, many AIE materials have been rationally designed and developed for two-photon fluorescence bioimaging (Gao et al., 2015; Wang et al., 2015, 2019a; Xiang et al., 2015; Zhu et al., 2015; Jiang et al., 2017; Yang et al., 2017; Chen M. et al., 2018; Yan et al., 2018; Gao Y. et al., 2020; Zhang R. et al., 2020). However, reviews on the application of AIE-active fluorescent materials for two-photon fluorescent bioimaging are rarely reported, except one review article about two-photon organic AIE dots (Lou et al., 2016). Considering some reviews have summarized the applications of AIE materials for cancer therapy (Gao and Tang, 2017; Hu et al., 2018; Zhang et al., 2018; Dai et al., 2020; He et al., 2020a; Wu and $\mathrm{Li}, 2020$ ), in this review, we will focus on the AIE-active materials for two-photon bioimaging. This review summarizes the latest literatures in the past 6 years and discusses the twophoton bioimaging applications of AIE-active materials from four aspects: fluorescence detection, in vitro cell imaging, ex vivo tissue imaging, and in vivo vascular imaging. At the end of this review, the future directions and developments of AIE-active materials for two-photon bioimaging will be discussed.

\section{BIOIMAGING APPLICATIONS}

\section{Fluorescent Detection}

As a signal gas transmitter, $\mathrm{H}_{2} \mathrm{~S}$ plays a vital role in regulating the different functions of life systems (Hong et al., 2018; Lv L. et al., 2020; Wang J. et al., 2020; Zhang D. et al., 2020). Yoon's group developed a two-photon AIE probe $\mathbf{1}$ based on the mechanism of excited-state intramolecular proton transfer (ESIPT) for fluorescent turn-on detection of $\mathrm{H}_{2} \mathrm{~S}$ (Figure 2A) (Chen et al., 2017). The probe 1 showed almost no fluorescence due to free motion and inhibited ESIPT effect. After reaction with $\mathrm{H}_{2} \mathrm{~S}$, the six-membered pyran ring of probe $\mathbf{1}$ opened and 


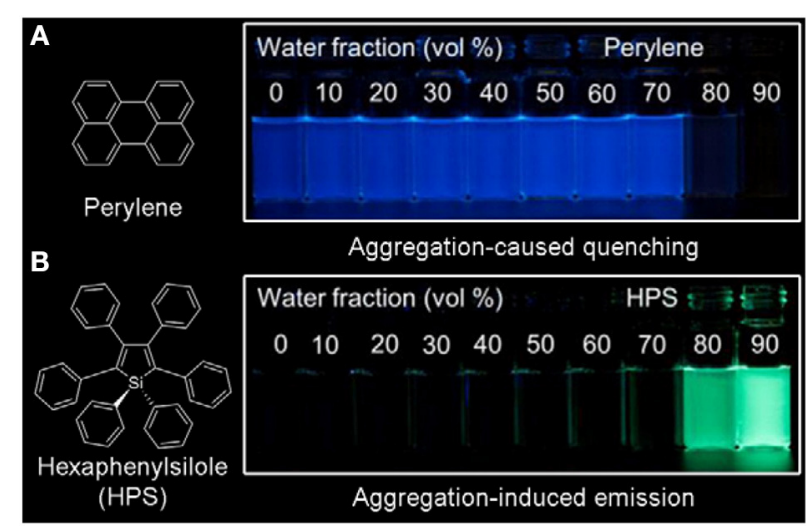

FIGURE 1 | Fluorescent photographs of (A) perylene and (B) hexaphenylsilole (HPS) in $\mathrm{THF} / \mathrm{H}_{2} \mathrm{O}$ mixture containing different water fractions under $365 \mathrm{~nm}$ UV irradiation (reproduced with permission from Mei et al., 2015; Copyright 2015 American Chemical Society)

the $\mathrm{H}$ atom in the phenolic hydroxyl group was bonded with the $\mathrm{N}$ atom in the adjacent benzothiazole to form compound 2, which showed dramatically enhanced fluorescence (about 80fold) because of ESIPT and AIE characteristics. The detection limit was calculated to be $41 \mathrm{nM}$. The probe 1 showed high selectivity and sensitivity toward $\mathrm{H}_{2} \mathrm{~S}$. The authors further applied the probe $\mathbf{1}$ for two-photon fluorescence imaging of $\mathrm{H}_{2} \mathrm{~S}$ in HeLa cells, rendering its high potential in investigating the biological and pathological roles of $\mathrm{H}_{2} \mathrm{~S}$ in the life system.

The changes of $\mathrm{pH}$ and viscosity in cells will affect the reaction rate and material and energy transfer rates of cells, which have important biological value for the analysis of various physiological activities of cells (Han et al., 2020; Kim et al., 2020; Ma et al., 2020; Zhang J. et al., 2020; Zhi et al., 2020). A novel AIE-active probe 3 based on a styrylquinoline derivative with excellent two-photon performance was designed and synthesized (Figure 2B) (Dou et al., 2019). Due to the AIE effect, the probe emitted yellow emission of $550 \mathrm{~nm}$ in solution. Based on the response principle of $\mathrm{N}$ atom in quinoline to $\mathrm{H}^{+}$(compound 4), the probe 3 exhibited good sensitivity toward $\mathrm{pH}$ with blue emission of $470 \mathrm{~nm}$ and a pKa value of 3.21. It also showed a good linearity with $\mathrm{pH}$ in the range $3.0-1.25$. In addition, due to its free motion feature, the AIE probe displayed enhanced yellow emission at $550 \mathrm{~nm}$ at high viscous solution (compound 3'). The two-photon absorption cross section was very high (up to 612 $\mathrm{GM}$ at $640 \mathrm{~nm}$ ). Further two-photon bioimaging of viscosity and $\mathrm{pH}$ in live HeLa cells was successfully carried out.

As one of the important reactive oxygen species, hypochlorite $\left(\mathrm{ClO}^{-}\right)$plays a very key role in modulating a set of biological processes in the life systems, such as signal transduction, inflammation, carcinogenesis and neurological diseases. Proper concentration can be highly effective for antibacterial, antiinflammatory and pro-inflammatory properties (Hong et al., 2019; Feng A. et al., 2020; Li L. et al., 2020; Zhong et al., 2020). However, the abnormal concentration of $\mathrm{ClO}^{-}$can react with various components, leading to cell damage, tissue destruction, and eventually many diseases. Ding et al. reported a two-photon AIE probe 5 for $\mathrm{ClO}^{-}$visualization (Figure 2C) (Zhang et al., 2019). The probe 5 emitted almost no fluorescence, due to strong intramolecular motion. After reaction with $\mathrm{ClO}^{-}$, the ethylene bonded to indole quaternary salt was destructed to result in compound $\mathbf{6}$ with significant blue-shift emission of $514 \mathrm{~nm}$. The probe showed fast response and a low detection limit of $13.2 \mathrm{nM}$ toward $\mathrm{ClO}^{-}$. The two-photon absorption cross section of probe 5 after reaction with $\mathrm{ClO}^{-}$was $15.3 \mathrm{GM}$ at $730 \mathrm{~nm}$. Additionally, the probe showed a good two-photon imaging performance for turn-on detection of $\mathrm{ClO}^{-}$in HeLa cells.

Alkaline phosphatase (ALP) is considered to be a key biomarker related to signal transduction and tumor metabolism. The overexpression of ALP is closely related to the occurrence, development and deterioration of tumor and can be used as one of the important clinical indexes (He et al., 2020c; Khatun et al., 2020; Xu J. et al., 2020). Yoon and Peng et al. developed a new two-photon probe 7 based on typical AIE building block quinoline-malonitrile (QM) for ALP monitoring and surgical tumor excision (Figure 2D) (Li H. et al., 2020). The amphiphilic water-soluble probe 7 self-assembled to form nanoaggregate in aqueous solution. Upon addition with ALP, the fluorescence of self-assembled compound $\mathbf{8}$ was boosted, and the detection limit was calculated to be $0.15 \mathrm{mU} / \mathrm{mL}$. The nanoprobe 7 could selectively light-up HeLa cells with overexpression of ALP, and was applied to monitor the down-regulation and up-regulation of ALP activity. Long-term high-fidelity cell imaging of up to $13 \mathrm{~h}$ was achieved. The authors used this probe for twophoton imaging of HeLa multicellular tumor spheroids with high penetration depth. In addition, the probe was also successfully used to distinguish tumor tissues from normal tissues in BABL/C mice bearing HepG-2 and HeLa xenografts and further to guide tumor resection.

\section{In vitro Cell Imaging}

Cells are one of the basic components of organisms. Each cell is composed of various organelles such as plasma membrane, mitochondria, lysosome, golgi apparatus, endoplasmic reticulum, nucleus, centrosome, microtubule, and microfilament. These structures are very important to the precise operation of cells and even the whole body, and diverse biochemical processes and physiological pathways that occur in life have more profound significance. Thus, the development of organellespecific biological probes makes it possible to study specific target organelles, which can reveal the location and morphology of organelles and monitor the changes of important physiological activities or organelle dysfunction for researchers.

As an important organelle in cells, endoplasmic reticulum plays a key role in cell metabolism, protein synthesis and transmission of intermediates and signal molecules (Zhang M.M. et al., 2020; Zhao et al., 2020). Tang's group reported an AIE material 9 based on cyanostillbene skeleton by simple functionalization (Figure 3A) (Alam et al., 2020). Interestingly, the zwitterionic donor-receptor-type AIE material 9 with positive-charged pyridinium and negative-charged sulfonic group can specifically target the endoplasmic reticulum in live cells. This AIE material 9 showed maximum emission wavelength 
A

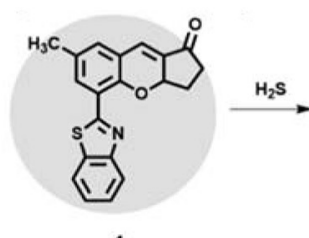

1

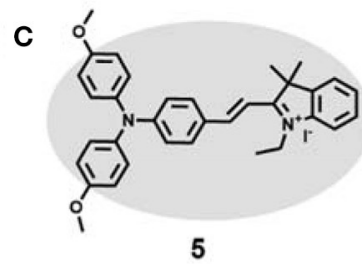

5

D

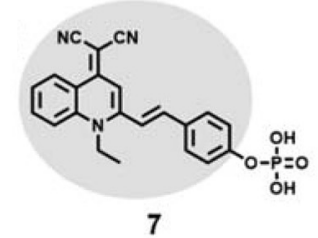

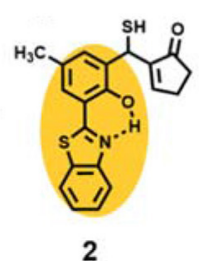

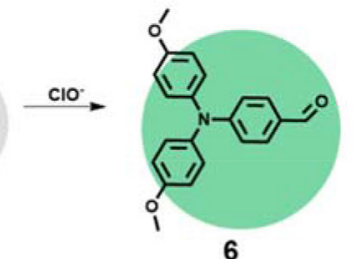

6

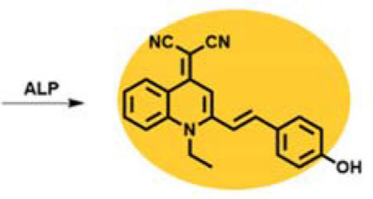

8
B

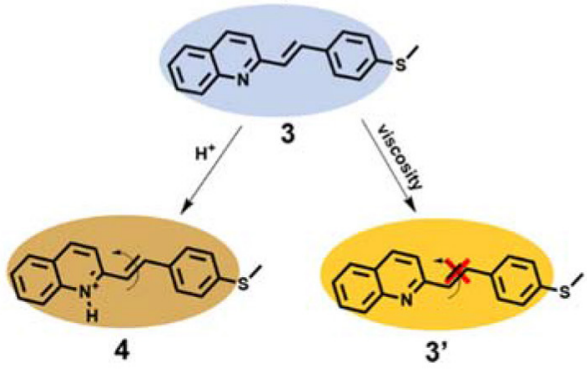

E

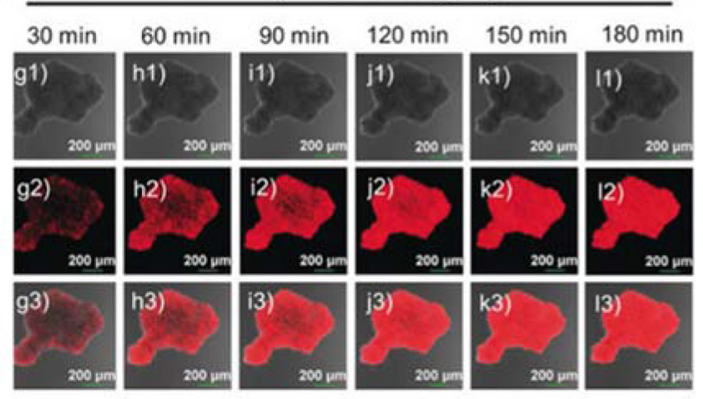

FIGURE 2 | (A) Working principle of AIE probe $\mathbf{1}$ for fluorescent two-photon detection of $\mathrm{H}_{2} \mathrm{~S}$. (B) Working principle of AlE probe $\mathbf{3}$ for fluorescent two-photon detection of $\mathrm{pH}$ and viscosity. (C) Working principle of AlE probe $\mathbf{5}$ for fluorescent two-photon detection of $\mathrm{ClO}^{-}$. (D) Working principle of AlE probe $\mathbf{7}$ for fluorescent two-photon detection of ALP and (E) two-photon imaging of HeLa multicellular tumor spheroids (reproduced with permission from Li H. et al., 2020 ; Copyright 2020 Wiley-VCH.).

under $620 \mathrm{~nm}$, two-photon absorption cross section of about 120 GM, and solid-state quantum efficiency of as high as $39.3 \%$. The imaging pattern of AIE material 9 was well overlapped with that of ER-Tracker Red with a high Pearson's correlation value of 0.85 . Further two-photon bioimaging of endoplasmic reticulum under $820 \mathrm{~nm}$ excitation was achieved.

Mitochondria are the "power factories" in cells, and their defects are closely related to aging, cancer and neurodegenerative diseases, including Alzheimer's disease, Huntington's disease and Parkinson's disease (Baines, 2010). Generally, positively charged fluorescent dyes can selectively locate in mitochondria via electrostatic interaction (Zhang et al., 2015; Jean et al., 2016; Liu et al., 2016). The photostable AIE material 10 was also confirmed to stain mitochondria in live HeLa cells (Figure 3B) (Qian et al., 2015). To expand its further application, Qian et al. applied these materials for two-photon imaging in primary neurons and mouse brain microglia. Because of high photostability of compound $\mathbf{1 0}$ in an aggregate state, they achieved long-term neuroimaging. Besides traditional fluorescence imaging, fluorescence lifetime imaging was also performed for mitochondria visualization. Chen et al. used the AIE material 11 for two-photon lifetime imaging of dual organelles: mitochondria and lipid droplets (Figure 3C) (Chen et al., 2015). The imaging data revealed that mitochondria incubated with compound $\mathbf{1 1}$ show longer lifetimes than lipid droplets. The authors further mapped the subcellular viscosity.

Photoactivatable fluorescent probes are preferable tools for organelle study with remarkably increased spatiotemporal resolution (Fay et al., 2020; Zou et al., 2020). Tang and Gao et al. developed two photoactivated AIE probes 12-1 and 12-2 for specific organelle imaging (Figure 3D) (Li et al., 2018). These AIE probes were in situ generated from easily available disulfide and thiol substrates through tandem S-S bond reduction and intramolecular cyclization reaction. Their subcellular organelle targeting ability could be regulated by the functionalized groups on the skeleton core. The probes $\mathbf{1 2 - 1}$ and 12-2 could selectively stain lipid droplets and lysosomes, respectively, and highresolution photoactivated imaging under one-photon and twophoton irradiation were also achieved. It should be noted that the fluorescence of the probes 12-1 and 12-2 can be activated faster under two-photon excitation than one-photon excitation.

\section{Ex vivo Tissue Imaging}

In situ and direct imaging of organelles in intact tissue can provide more intrinsic and accurate information than cells in vitro. On the one hand, the biological environments of the two are different. The cells in the live tissues are in the extracellular matrix, while the cells in vitro are in the artificial culture medium. On the other hand, the cells in vitro are generally immortalized cells that can be infinitely added, and their original differentiation function has been destroyed. In a word, the process of ex vivo tissue imaging is more complex and difficult than that of in vitro cell imaging, and the requirements of probes are more stringent.

Recent studies showed that hydrophobic dyes with high $\log \mathrm{P}$ (n-octanol/water partition coefficient) value are inclined to locate in lipid droplets (Zhao et al., 2019; Wang L. et al., 2020; Ye 


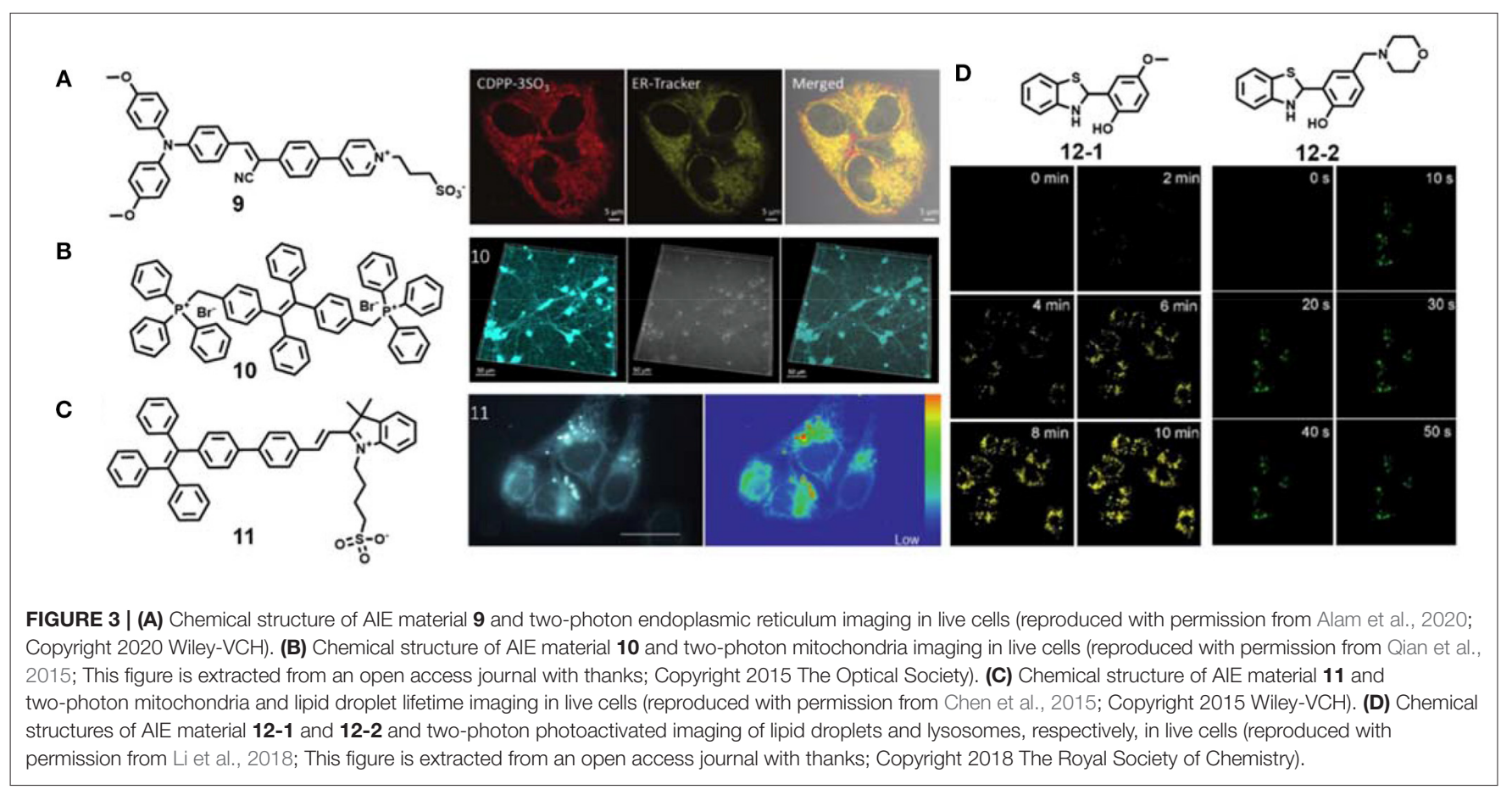

et al., 2020; Zhang F. et al., 2020; Zhang X. et al., 2020). A few fluorescent dyes have been applied for two-photon lipid droplet imaging in live cells and fixed tissues (Collot et al., 2018; Fam et al., 2018). However, fluorescent probes for two-photon imaging of lipid droplets in live tissues are rarely reported. Tang and $\mathrm{Yu}$ et al. synthesized a group of two-photon AIE fluorescence probes capable of selective staining lipid droplets in live cells and live tissues (Niu et al., 2018). These AIE probes exhibited excellent photophysical properties: large Stokes shift (>100 nm), high solid-state fluorescence quantum yield (30\%), good twophoton absorption cross section (45-100 GM at $860 \mathrm{~nm}$ ), high biocompatibility and excellent photostability. Rapid and specific staining lipid droplets in live cells at an ultralow concentration $(50 \mathrm{nM})$ was achieved. Such concentration is the lowest value for lipid droplet staining in live cells reported so far. The authors used probe 13 (Figure 4A) as an example to successfully achieve two-photon specific imaging of lipid droplets in live mouse liver tissues at a depth of about $70 \mu \mathrm{m}$ (Figure 4B).

Later, Tang's team developed a family of far-red and NIR AIE materials based on a carbazole-bridged push-pull framework (Zheng et al., 2018). Among these AIE materials, the compound DCMa could two-photon image lipid droplets at the depth of $129 \mu \mathrm{m}$ in live mouse liver tissues, and the compound DCPy showed two-photon deep-tissue imaging of mitochondria in live mouse muscle tissues $(77 \mu \mathrm{m})$. Subsequently, the positively charged AIE material 14 (Figure 4A) was also reported in their group (Niu et al., 2019a). The compound $\mathbf{1 4}$ showed large Stokes shift (>180 nm), high fluorescence quantum yield (12.8$13.7 \%)$, and excellent photostability under both one- and twophoton continuous irradiation. Moreover, the probe achieved the ex vivo two-photon depth tissue imaging of rat skeletal muscle mitochondria at the penetration depth of up to $100 \mu \mathrm{m}$ (Figure 4C).

Besides small AIE dyes, AIE nanomaterials by a simple nanoprecipitation method were also fabricated for ex vivo twophoton tissue imaging (Liu et al., 2019). Recently, Tang's group prepared red emissive AIE dots based on an efficient solidstate red-emissive AIE compound 15 (Figure 4A) with a high fluorescence quantum yield of $34.1 \%$ (Qin et al., 2018). The AIE dots exhibited a large two-photon absorption cross section value of $310 \mathrm{GM}$ at $900 \mathrm{~nm}$. The deep-tissue imaging performance of the AIE dots in mouse liver excited by a two-photon pulse laser $(>200 \mu \mathrm{m})$ was obviously better than that of one-photon imaging $(<100 \mu \mathrm{m})$ (Figure 4D). They also demonstrated their two-photon deep-tissue imaging of the blood vessels in mouse ears and brain. Later, they unexpectedly developed a red-emissive organic AIE material 16 (Figure 4A) with excellent fluorescence quantum yield $(37.6 \%)$, large two-photon absorption cross section (508 GM) and high biocompatibility (Niu et al., 2019b). The fabricated AIE nanoparticles (NPs) based on compound $\mathbf{1 6}$ could specifically stain lysosomes in live cells. In addition, highresolution two-photon deep tissue imaging of this AIE NPs in tumor tissue under $880 \mathrm{~nm}$ excitation was obtained, and the two-photon imaging performance was better than one-photon excitation (Figure 4E). Further use of this NPs for long-term imaging of tumors in mice was achieved. The AIE NPs show great potential in two-photon deep tissue bioimaging and long-term dynamic tracking of tumor metastasis.

\section{In vivo Vasculatures Imaging}

Blood vessels play an essential role in the growth and metastasis of solid tumors, and can transport nutrients and oxygen in 
A<smiles></smiles>

13<smiles>CCOc1cc(N(CC)CC)ccc1C=C(C)Cc1ccc(-c2cc[n+](C)c(C)c2)cc1</smiles>

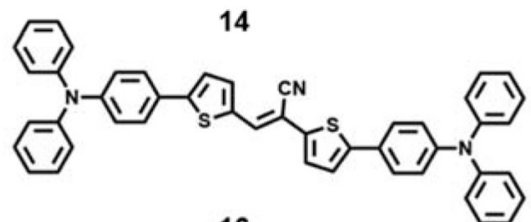

16

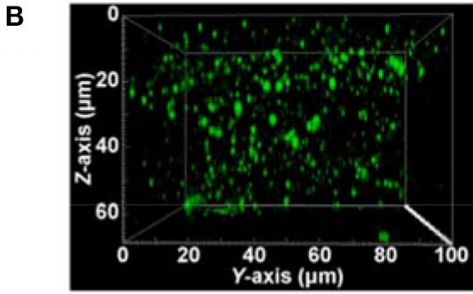

C

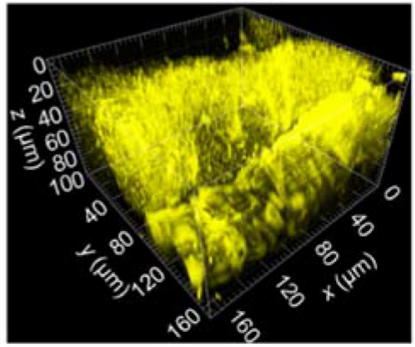

D

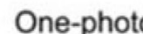

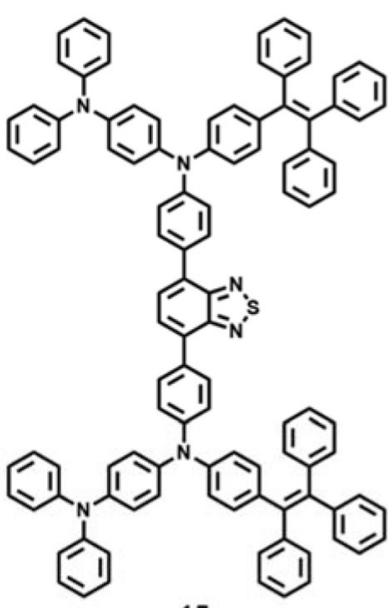

15

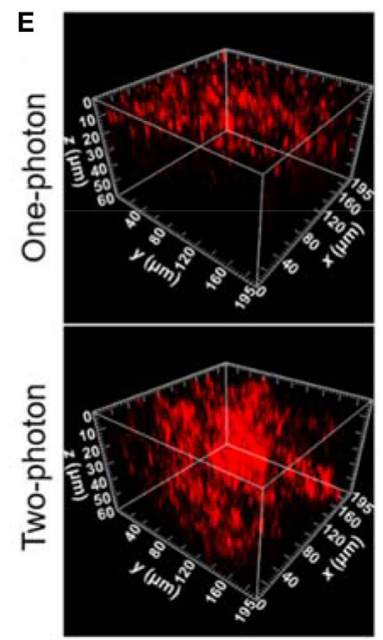

FIGURE 4 | (A) Chemical structures of AIE materials 13-16 for two-photon tissue imaging. (B) Reconstructed 3D two-photon fluorescence imaging of lipid droplets in live mouse liver tissues incubated with AIE material 13 (reproduced with permission from Niu et al., 2018; Copyright 2018 American Chemical Society). (C) Reconstructed 3D two-photon fluorescence imaging of live mice muscle tissues incubated with AIE material $\mathbf{1 4}$ (reproduced with permission from Niu et al., 2019a; Copyright 2019 Elsevier). (D) One-photon and two-photon fluorescent images of mouse liver by intravenous injection with compound $\mathbf{1 5}$ based AlE dots (reproduced with permission from Qin et al., 2018; This figure is extracted from an open access journal with thanks; Copyright 2018 The Royal Society of Chemistry). (E) Reconstructed 3D One-photon and two-photon fluorescent images of mouse tumor by intratumor injection with compound $\mathbf{1 6}$ based AIE NPs (reproduced with permission from Niu et al., 2019b; Copyright 2019 American Chemical Society).

the tumor microenvironment (Dewhirst and Secomb, 2017; Li et al., 2021). Tumor blood vessels are usually characterized by structural and functional abnormalities, vascular leakage, dilatation, bending of blood vessels, increasing non-uniformity of tumor blood flow, and so on (Tozer et al., 2005). Cerebrovascular abnormalities are related to cerebrovascular diseases such as stroke, vascular malformations, aneurysms, and transient ischemic attacks (Chen C.-J. et al., 2018; Lin et al., 2018). Therefore, the utilization of an in vivo two-photon fluorescence microscope with cell resolution and promising sensitivity can not only effectively identify and monitor the vascular structure, morphology, and normalization process of cerebrovascular systems and tumors, but also provide valuable information for the diagnosis and treatment of the disease. Moreover, this method reduces the light absorption and scattering of biological tissue, and achieves better light transmittance and deeper imaging depth.

Liu and co-authors developed efficient near-infrared AIE dots based on the compound $\mathbf{1 7}$ (Figure 5A) (Wang et al., 2019b). The fabricated AIE dots showed excellent properties: high quantum yield $(19 \pm 1 \%)$ and ultralarge two-photon absorption cross section $\left(7.63 \times 10^{4} \mathrm{GM}\right.$ at $\left.1,200 \mathrm{~nm}\right)$. Under the two-photon NIR-II excitation $(1,200 \mathrm{~nm})$, the mouse brain vasculatures labeled by the AIE dots could be clearly imaged at an ultradeep depth of $924 \mu \mathrm{m}$ (Figure 5A). They successfully used AIE dots to distinguish the tumor vessels from normal vessels, and realized 
A
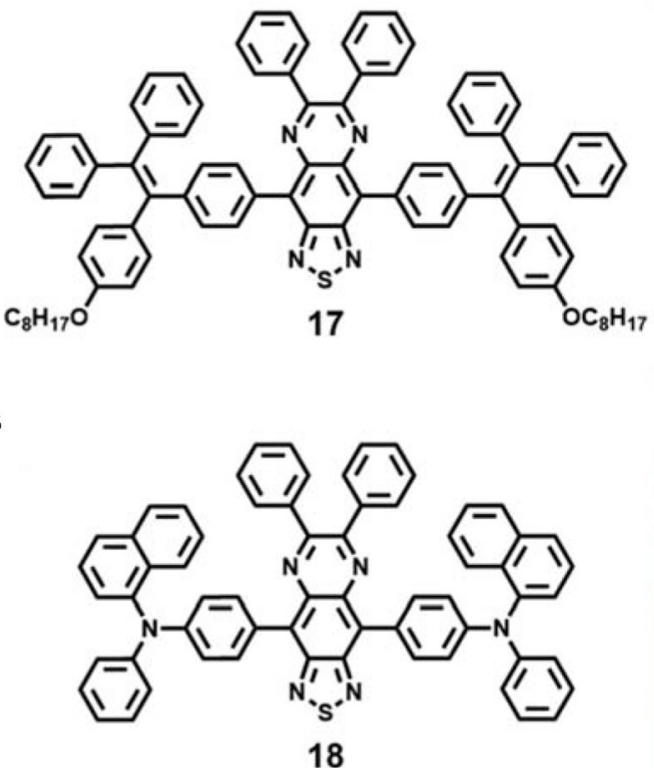
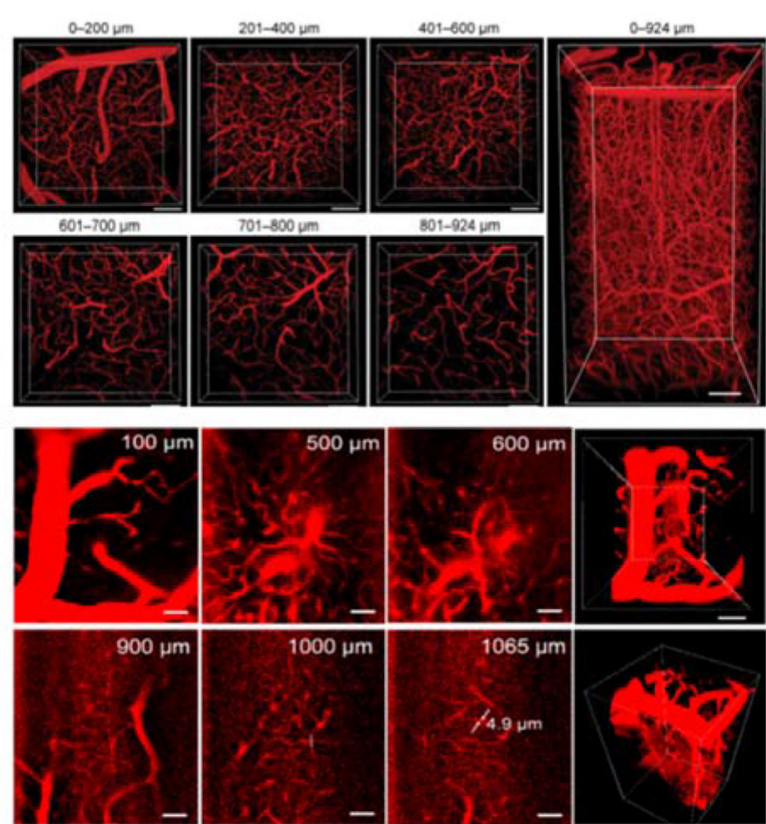

FIGURE 5 | (A) Chemical structures of AIE material 17 and 3D two-photon intravital imaging of mouse brain vasculature network at different penetration depths (reproduced with permission from Wang et al., 2019b; Copyright 2019 Wiley-VCH). (B) Chemical structures of AlE material 18 and $3 \mathrm{D}$ two-photon imaging of mouse brain blood vessels at different penetration depths (reproduced with permission from Qi et al., 2018; Copyright 2018 American Chemical Society).

the non-invasive real-time imaging of the deep tumor vascular network with large penetration depth $(670 \mu \mathrm{m})$ and high signalto-background ratio (about 120) under the two-photon NIR-II excitation. This work opens up a new avenue for effective nearinfrared materials excited by two-photon NIR-II light in vivo tumor imaging.

Tang and Qian et al. fabricated other AIE dots based on red-shifted NIR emissive AIE compound $\mathbf{1 8}$ with a maximum emission wavelength of $810 \mathrm{~nm}$ for ultradeep intravital twophoton fluorescence bioimaging (Figure 5B) (Qi et al., 2018). The water-soluble AIE dots exhibited superior large two-photon absorption cross section $\left(1.22 \times 10^{3} \mathrm{GM}\right.$ at $\left.1,300 \mathrm{~nm}\right)$. Under two-photon 1,300 nm NIR-II light irradiation, 3D blood vessels outside white matter $(>840 \mu \mathrm{m})$ and even in the hippocampus $(>960 \mu \mathrm{m})$ were successfully constructed at ultrahigh spatial resolution $(<3.5 \mu \mathrm{m})$, and $5 \mu \mathrm{m}$ vessels in the mouse brain were clearly visible at the depth of $1,065 \mu \mathrm{m}$ (Figure 5B), which was one of the deepest penetration depths and the best spatial resolution reported so far.

\section{CONCLUSION AND OUTLOOK}

AIE materials have become a preferential choice for two-photon fluorescence bioimaging because of their strong fluorescence and excellent photostability in high concentration or aggregation states. This review mainly summarizes the recent advances of AIE-active materials for two-photon bioimaging with some representative examples in four areas: fluorescence detection, in vitro cell imaging, ex vivo tissue imaging, and in vivo vasculature imaging. Though some interesting progress has been achieved, there are some unsolved problems and challenges which still need to be overcome.

New recognition units need to be rationally incorporated into the skeleton of AIE-active two-photon materials to extend the analyte detection ranges, such as DNA, protein, enzyme, chiral molecules, and so on. However, for AIE probes, the detection limit is a critical parameter to be carefully considered. In addition, subcellular organelle targeted AIE-active twophoton materials should be switched to some other important organelles like golgi apparatus, nucleus, and nucleolus, which could be possibly achieved by conjugation with specific organelletargeting peptides. It should be noted that the specificity of these organelle targeted AIE-active materials could be altered a lot in neuron cells. In some point, the development of such materials for specific organelle targeting in neuron cells is challenging. The majority of AIE materials exhibit small to moderate two-photon absorption cross section, so enhancing the two-photon absorption cross section is still an important issue. Generally, extending the $\pi$-conjugation length of AIE skeletons and introducing strong electron donor and acceptor groups to enhance the intramolecular charge transfer effects are two widely adopted strategies to improve the two-photon absorption as well as to enable the red shift of absorption and emission. However, these strategies can result in high hydrophobicity of AIE materials. The balance between hydrophobicity and penetrability to live samples needs careful consideration. On the other hand, the 
twisted intramolecular charge transfer (TICT) effect should be also considered, as the TICT effect is detrimental for AIE materials especially NIR emissive ones. It should be also added that the fabrication of composite two-photon AIE-active materials with other materials like inorganic quantum dots is an effective method to render the composite materials with multifunctionalities, such as multimode imaging and activitybased cancer diagnosis. Furthermore, traditional chemotherapy and modern phototherapy (photodynamic and photothermal therapy) based on drugs and photosensitizers, respectively, have been demonstrated to show satisfying therapeutic effects. Combined with two-photon fluorescence imaging of AIE-active materials, such imaging-guided therapy could emerge as an effective modality for precise spatiotemporal control of cancer therapy. Therefore, there is still much room to improve and develop many fascinating AIE-active materials for diverse twophoton biomedical imaging. We hope this review can shed new light on future two-photon bioimaging application of AIE-active materials.

\section{REFERENCES}

Alam, P., He, W., Leung, N. L. C., Ma, C., Kwok, R. T. K., Lam, J. W. Y., et al. (2020). Red AIE-active fluorescent probes with tunable organelle-specific targeting. Adv. Funct. Mater. 30:1909268. doi: 10.1002/adfm.201909268

An, B.-K., Gierschner, J., and Park, S. Y. (2012). $\pi$-conjugated cyanostilbene derivatives: a unique self-assembly motif for molecular nanostructures with enhanced emission and transport. Acc. Chem. Res. 45, 544-554. doi: $10.1021 /$ ar2001952

An, B.-K., Kwon, S.-K., Jung, S.-D., and Park, S. Y. (2002). Enhanced emission and its switching in fluorescent organic nanoparticles. J. Am. Chem. Soc. 124, 14410-14415. doi: 10.1021/ja0269082

Baines, C. P. (2010). The cardiac mitochondrion: nexus of stress. Ann. Rev. Physiol. 72, 61-80. doi: 10.1146/annurev-physiol-021909-135929

Cao, H., Yue, Z., Gao, H., Chen, C., Cui, K., Zhang, K., et al. (2019). In vivo real-time imaging of extracellular vesicles in liver regeneration via aggregation-induced emission luminogens. ACS Nano 13, 3522-3533. doi: 10.1021/acsnano.8b09776

Chen, C.-J., Kumar, J. S., Chen, S. H., Ding, D., Buell, T. J., Sur, S., et al. (2018). Optical coherence tomography future applications in cerebrovascular imaging. Stroke 49, 1044-1050. doi: 10.1161/STROKEAHA.117.019818

Chen, L., Wu, D., Lim, C. S., Kim, D., Nam, S.-J., Lee, W., et al. (2017). A twophoton fluorescent probe for specific detection of hydrogen sulfide based on a familiar ESIPT fluorophore bearing AIE characteristics. Chem. Commun. 53, 4791-4794. doi: 10.1039/C7CC01695F

Chen, M., Qin, A., Lam, J. W. Y., and Tang, B. Z. (2020). Multifaceted functionalities constructed from pyrazine-based AIEgen system. Coord. Chem. Rev. 422:213472. doi: 10.1016/j.ccr.2020.213472

Chen, M., Xie, W., Li, D., Zebibula, A., Wang, Y., Qian, J., et al. (2018). Utilizing a pyrazine-containing aggregation-induced emission luminogen as an efficient photosensitizer for imaging-guided two-photon photodynamic therapy. Chem. Eur. J. 24, 16603-16608. doi: 10.1002/chem.201803580

Chen, S., Hong, Y., Zeng, Y., Sun, Q., Liu, Y., Zhao, E., et al. (2015). Mapping live cell viscosity with an aggregation-induced emission fluorogen by means of two-photon fluorescence lifetime imaging. Chem. Eur. J. 21, 4315-4320. doi: 10.1002/chem.201405658

Chen, Y., Lam, J. W. Y., Kwok, R. T. K., Liu, B., and Tang, B. Z. (2019). Aggregation-induced emission: fundamental understanding and future developments. Mater. Horiz. 6, 428-433. doi: 10.1039/C8MH01331D

Chen, Y., Zhang, W., Zhao, Z., Cai, Y., Gong, J., Kwok, R. T. K., et al. (2018). An easily accessible ionic aggregation-induced emission luminogen

\section{AUTHOR CONTRIBUTIONS}

All authors listed have made a substantial, direct and intellectual contribution to the writing process of this article, and approved the manuscript.

\section{FUNDING}

This work was supported by the National Natural Science Foundation of China (51773111, 21672130, 51273107, 51273175, and 51573158), the Natural Science Foundation of Shandong Province, China (ZR2018BB021 and ZR2017ZC0227), the Fundamental Research Funds of Shandong University (2017JC011 and 2018JC030), the Special Fund of Taishan Scholars Project of Shandong Province, China (tsqn201909012), the Opening Fund of Key Laboratory of Photochemical Conversion and Optoelectronic Materials, TIPC, CAS (PCOM202001), and the Program of Qilu Young Scholars of Shandong University.

with hydrogen-bonding-switchable emission and wash-free imaging ability. Angew. Chem. Int. Ed. 57, 5011-5015. doi: 10.1002/anie.201800772

Collot, M., Fam, T. K., Ashokkumar, P., Faklaris, O., Galli, T., Danglot, L., et al. (2018). Ultrabright and fluorogenic probes for multicolor imaging and tracking of lipid droplets in cells and tissues. J. Am. Chem. Soc. 140, 5401-5411. doi: $10.1021 /$ jacs.7b12817

Dai, J., Wu, X., Ding, S., Lou, X., Xia, F., Wang, S., et al. (2020). Aggregationinduced emission photosensitizers: from molecular design to photodynamic therapy. J. Med. Chem. 63, 1996-2012. doi: 10.1021/acs.jmedchem.9b02014

Dewhirst, M. W., and Secomb, T. W. (2017). Transport of drugs from blood vessels to tumour tissue. Nat. Rev. Cancer 17, 738-750. doi: 10.1038/nrc.2017.93

Ding, S., Liu, M., and Hong, Y. (2018). Biothiol-specific fluorescent probes with aggregation-induced emission characteristics. Sci. China Chem. 61, 882-891. doi: $10.1007 /$ s11426-018-9300-5

Dou, Y., Kenry, L.iu, J., Zhang, F., Cai, C., and Zhu, Q. (2019). 2-Styrylquinolinebased two-photon AIEgens for dual monitoring of $\mathrm{pH}$ and viscosity in living cells. J. Mater. Chem. B 7, 7771-7775. doi: 10.1039/C9TB02036E

Fam, T. K., Klymchenko, A. S., and Collot, M. (2018). Recent advances in fluorescent probes for lipid droplets. Materials 11:1768. doi: 10.3390/ma11091768

Fay, R., Linden, A., and Holland, J. P. (2020). phototag: photoactivatable fluorophores for protein labeling. Org. Lett. 22, 3499-3503. doi: 10.1021/acs.orglett.0c00957

Feng, A., Liu, P., Liang, Q., Zhang, X., Huang, L., Jia, Y., et al. (2020). A new carbazole-based colormetric and ratiometric fluorescent probe for hypochlorite sensing in living cells and zebrafishes. Dyes Pigm. 180:108492. doi: 10.1016/j.dyepig.2020.108492

Feng, H.-T., Zou, S., Chen, M., Xiong, F., Lee, M.-H., Fang, L., et al. (2020). Tuning push-pull electronic effects of aiegens to boost the theranostic efficacy for colon cancer. J. Am. Chem. Soc. 142, 11442-11450. doi: 10.1021/jacs.0c02434

Gao, M., and Tang, B. Z. (2017). Aggregation-induced emission probes for cancer theranostics. Drug Discov. Today 22, 1288-1294. doi: 10.1016/j.drudis.2017.07.004

Gao, Y., Feng, G., Jiang, T., Goh, C., Ng, L., Liu, B., et al. (2015). Biocompatible nanoparticles based on Diketo-Pyrrolo-Pyrrole (DPP) with aggregationinduced red/nir emission for in vivo two-photon fluorescence imaging. $A d v$. Funct. Mater. 25, 2857-2866. doi: 10.1002/adfm.201500010

Gao, Y., Zhang, H., He, Z., Fang, F., Wang, C., Zeng, K., et al. (2020). Multicationic AIEgens for unimolecular photodynamic theranostics and two-photon fluorescence bioimaging. Mater. Chem. Front. 4, 1623-1633. doi: 10.1039/D0QM00119H 
Gao, Y. T., Zhang, H. K., He, Z. Y., Fang, F., Wang, C., Zeng, K. H., et al. (2020). Multicationic AIEgens for unimolecular photodynamic theranostics and two-photon fluorescence bioimaging. Mater. Chem. Front. 4, 1623-1633. doi: $10.1039 / \mathrm{d} 0 \mathrm{qm} 00119 \mathrm{~h}$

Guo, Z., Yan, C., and Zhu, W.-H. (2020). High-performance quinolinemalononitrile core as a building block for the diversity-oriented synthesis of AIEgens. Angew. Chem. Int. Ed. 59, 9812-9825. doi: 10.1002/anie.201913249

Han, D., Yi, J., Liu, C., Liang, L., Huang, K., Jing, L., et al. (2020). A fluoran-based viscosity probe with high-performance for lysosome-targeted fluorescence imaging. Spectrochim. Acta A 238:118405. doi: 10.1016/j.saa.2020.118405

He, X., Xiong, L.-H., Huang, Y., Zhao, Z., Wang, Z., Lam, J. W. Y., et al. (2020a). AIE-based energy transfer systems for biosensing, imaging, and therapeutics. TrAC Trend. Anal. Chem. 122:115743. doi: 10.1016/j.trac.2019.115743

He, X., Yang, Y., Guo, Y., Lu, S., Du, Y., Li, J.-J., et al. (2020b). Phage-guided targeting, discriminative imaging, and synergistic killing of bacteria by AIE bioconjugates. J. Am. Chem. Soc. 142, 3959-3969. doi: 10.1021/jacs.9b12936

He, Y., Yu, J., Hu, X., Huang, S., Cai, L., Yang, L., et al. (2020c). An activity-based fluorescent probe and its application for differentiating alkaline phosphatase activity in different cell lines. Chem. Commun. 56, 13323-13326. doi: 10.1039/D0CC06129H

Hong, Y., Lam, J. W. Y., and Tang, B. Z. (2011). Aggregation-induced emission. Chem. Soc. Rev. 40, 5361-5388. doi: 10.1039/clcs15113d

Hong, Y. X., Wang, H., Xue, M. J., Zhang, P. S., Liu, W. Q., Chen, S., et al. (2019). Rational design of ratiometric and lysosome-targetable AIE dots for imaging endogenous $\mathrm{HClO}$ in live cells. Mater. Chem. Front. 3, 203-208. doi: 10.1039/C8QM00511G

Hong, Y. X., Zhang, P. S., Wang, H., Yu, M. L., Gao, Y., and Chen, J. (2018). Photoswitchable AIE nanoprobe for lysosomal hydrogen sulfide detection and reversible dual-color imaging. Sens. Actuat. B-Chem. 272, 340-347. doi: 10.1016/j.snb.2018.05.175

$\mathrm{Hu}, \mathrm{F}$., Xu, S., and Liu, B. (2018). Photosensitizers with aggregation-induced emission: materials and biomedical applications. Adv. Mater. 30:1801350. doi: 10.1002/adma.201801350

Hu, M., Feng, H.-T., Yuan, Y.-X., Zheng, Y.-S., and Tang, B. Z. (2020). Chiral aiegens - chiral recognition, CPL materials and other chiral applications. Coord. Chem. Rev. 416:213329. doi: 10.1016/j.ccr.2020.213329

Huang, L., Tao, H., Zhao, S., Yang, K., Cao, Q.-Y., and Lan, M. (2020). A tetraphenylethylene-based aggregation-induced emission probe for fluorescence turn-on detection of lipopolysaccharide in injectable water with sensitivity down to picomolar. Ind. Eng. Chem. Res. 59, 8252-8258. doi: 10.1021 /acs.iecr.0c01408

Jean, S. R., Ahmed, M., Lei, E. K., Wisnovsky, S. P., and Kelley, S. O. (2016). Peptide-mediated delivery of chemical probes and therapeutics to mitochondria. Acc. Chem. Res. 49, 1893-1902. doi: $10.1021 /$ acs.accounts.6b00277

Jiang, M., Gu, X., Lam, J. W. Y., Zhang, Y., Kwok, R. T. K., Wong, K. S., et al. (2017). Two-photon AIE bio-probe with large stokes shift for specific imaging of lipid droplets. Chem. Sci. 8, 5440-5446. doi: 10.1039/C7SC 01400G

Khatun, S., Biswas, S., Mahanta, A. K., Joseph, M. M., Vidyalekshmi, M. S., Podder, A., et al. (2020). Biocompatible fluorescent probe for detecting mitochondrial alkaline phosphatase activity in live cells. J. Photochem. Photob. B 212, 112043-112043. doi: 10.1016/j.jphotobiol.2020.112043

Kim, S. Y., Podder, A., Lee, H., Cho, Y.-J., Han, E. H., Khatun, S., et al. (2020). Self-assembled amphiphilic fluorescent probe: detecting $\mathrm{pH}-$ fluctuations within cancer cells and tumour tissues. Chem. Sci. 11, 9875-9883. doi: 10.1039/D0SC03795H

Kong, Y. J., Yan, Z. P., Li, S., Su, H. F., Li, K., Zheng, Y. X., et al. (2020). Photoresponsive propeller-like chiral AIE Cu(I) clusters. Angew. Chem. Int. Ed. 59, 5336-5340. doi: 10.1002/anie.201915844

Li, H., Yao, Q., Xu, F., Li, Y., Kim, D., Chung, J., et al. (2020). An activatable aiegen probe for high-fidelity monitoring of overexpressed tumor enzyme activity and its application to surgical tumor excision. Angew. Chem. Int. Ed. 59, 10186-10195. doi: 10.1002/anie.202001675

Li, L., Wang, X., Sun, C., Xu, T., Yang, Z., Zhang, Z., et al. (2020). Design of a twophoton fluorescent probe for ratiometric imaging of endogenous hypochlorite in mitochondria. Dyes Pigm. 181:108548. doi: 10.1016/j.dyepig.2020.10 8548
Li, Q., Li, Y., Min, T., Gong, J., Du, L., Phillips, D. L., et al. (2020). Timedependent photodynamic therapy for multiple targets: a highly efficient aie-active photosensitizer for selective bacterial elimination and cancer cell ablation. Angew. Chem. Int. Ed. 59, 9470-9477. doi: 10.1002/anie.201909706

$\mathrm{Li}, \mathrm{Q}$., and Li, Z. (2017). The strong light-emission materials in the aggregated state: what happens from a single molecule to the collective group. Adv. Sci. 4:1600484. doi: $10.1002 /$ advs.201600484

Li, S., Ling, X., Lin, Y., Qin, A., Gao, M., and Tang, B. Z. (2018). In situ generation of photoactivatable aggregation-induced emission probes for organelle-specific imaging. Chem. Sci. 9, 5730-5735. doi: 10.1039/C8SC01887A

Li, Y., Hu, D., Sheng, Z., Min, T., Zha, M., Ni, J.-S., et al. (2021). Self-assembled AIEgen nanoparticles for multiscale NIR-II vascular imaging. Biomaterials 264:120365. doi: 10.1016/j.biomaterials.2020.120365

Li, Y. J., Zhang, H. T., Chen, X. Y., Gao, P. F., and Hu, C.-H. (2019). A multifunctional AIEgen with high cell-penetrating ability for intracellular fluorescence assays, imaging and drug delivery. Mater. Chem. Front. 3, 1151-1158. doi: 10.1039/C9QM00089E

Li, Y. Y., Liu, S. J., Ni, H. W., Zhang, H., Zhang, H. Q., Chuah, C., et al. (2020). ACQ-to-AIE transformation: tuning molecular packing by regioisomerization for two-photon nir bioimaging. Angew. Chem. Int. Ed. 59, 12822-12826. doi: 10.1002/anie.202005785

Li, Y., Tang, R., Liu, X., Gong, J., Zhao, Z., Sheng, Z., et al. (2020). Bright aggregation-induced emission nanoparticles for two-photon imaging and localized compound therapy of cancers. ACS Nano. doi: 10.1021 /acsnano.0c05610

Lin, A., Rawal, S., Agid, R., and Mandell, D. M. (2018). Cerebrovascular imaging: which test is best? Neurosurgery 83, 5-18. doi: 10.1093/neuros/nyx325

Liu, H., Zhang, P., Zhang, C., Chen, J., and Jiang, J.-H. (2020). Self-assembly of a dual-targeting and self-calibrating ratiometric polymer nanoprobe for accurate hypochlorous acid imaging. ACS Appl. Mater. Interfaces 12, 45822-45829. doi: 10.1021/acsami.0c13857

Liu, L.-J., Liu, W., Ji, G., Wu, Z.-Y., Xu, B., Qian, J., et al. (2019). NIR emission nanoparticles based on fret composed of aie luminogens and nir dyes for two-photon fluorescence imaging. Chinese J. Poly. Sci. 37, 401-408. doi: 10.1007/s10118-019-2206-3

Liu, Y., Zhou, J., Wang, L., Hu, X., Liu, X., Liu, M., et al. (2016). A cyanine dye to probe mitophagy: simultaneous detection of mitochondria and autolysosomes in live cells. J. Am. Chem. Soc. 138, 12368-12374. doi: 10.1021/jacs.6b04048

Looney, M. R., Thornton, E. E., Sen, D., Lamm, W. J., Glenny, R. W., and Krummel, M. F. (2011). Stabilized imaging of immune surveillance in the mouse lung. Nat. Methods 8, 91-96. doi: 10.1038/nmeth.1543

Lou, X., Zhao, Z., and Tang, B. Z. (2016). Organic dots based on AIEgens for two-photon fluorescence bioimaging. Small 12, 6430-6450. doi: $10.1002 /$ smll.201600872

Luo, J. D., Xie, Z. L., Lam, J. W. Y., Cheng, L., Chen, H. Y., Qiu, C. F., et al. (2001). Aggregation-induced emission of 1-methyl-1,2,3,4,5-pentaphenylsilole. Chem. Commun. 1740-1741. doi: 10.1039/b105159h

Lv, L., Luo, W., and Diao, Q. (2020). A novel ratiometric fluorescent probe for selective detection and imaging of H2S. Spectrochim. Acta. A 246, 118959-118959. doi: 10.1016/j.saa.2020.118959

Lv, Z., Li, L., Man, Z., Xu, Z., Cui, H., Zhan, R., et al. (2020). Polarity-activated super-resolution imaging probe for the formation and morphology of amyloid fibrils. Nano Res. 13, 2556-2563. doi: 10.1007/s12274-020-2899-1

Ma, C., Sun, W., Xu, L., Qian, Y., Dai, J., Zhong, G., et al. (2020). A minireview of viscosity-sensitive fluorescent probes: design and biological applications. J. Mater. Chem. B 8, 9642-9651. doi: 10.1039/D0TB01146K

Mao, H.-T., Li, G.-F., Shan, G.-G., Wang, X.-L., and Su, Z.-M. (2020). Recent progress in phosphorescent $\operatorname{Ir}(\mathrm{III})$ complexes for nondoped organic lightemitting diodes. Coord. Chem. Rev. 413:213283. doi: 10.1016/j.ccr.2020.213283

Mei, J., Leung, N. L. C., Kwok, R. T. K., Lam, J. W. Y., and Tang, B. Z. (2015). Aggregation-induced emission: together we shine, united we soar! Chem. Rev. 115, 11718-11940. doi: 10.1021/acs.chemrev.5b00263

Ni, J.-S., Min, T., Li, Y., Zha, M., Zhang, P., Ho, C. L., et al. (2020). Planar AIEgens with enhanced solid-state luminescence and ros generation for multidrugresistant bacteria treatment. Angew. Chem. Int. Ed. 59, 10179-10185. doi: $10.1002 /$ anie. 202001103

Niu, G., Zhang, R., Gu, Y., Wang, J., Ma, C., Kwok, R. T. K., et al. (2019a). Highly photostable two-photon NIR AIEgens with tunable 
organelle specificity and deep tissue penetration. Biomaterials 208, 72-82. doi: 10.1016/j.biomaterials.2019.04.002

Niu, G., Zhang, R., Kwong, J. P. C., Lam, J. W. Y., Chen, C., Wang, J., et al. (2018). Specific two-photon imaging of live cellular and deep-tissue lipid droplets by lipophilic aiegens at ultralow concentration. Chem. Mater. 30, 4778-4787. doi: 10.1021/acs.chemmater.8b01943

Niu, G., Zhang, R., Shi, X., Park, H., Xie, S., Kwok, R. T. K., et al. (2020). AIE luminogens as fluorescent bioprobes. Trend. Anal. Chem. 123:115769. doi: $10.1016 /$ j.trac.2019.115769

Niu, G., Zheng, X., Zhao, Z., Zhang, H., Wang, J., He, X., et al. (2019b). Functionalized acrylonitriles with aggregation-induced emission: structure tuning by simple reaction-condition variation, efficient red emission, and two-photon bioimaging. J. Am. Chem. Soc. 141, 15111-15120. doi: $10.1021 /$ jacs.9b06196

Qi, J., Sun, C., Li, D., Zhang, H., Yu, W., Zebibula, A., et al. (2018). Aggregationinduced emission luminogen with near-infrared-II excitation and nearinfrared-i emission for ultradeep intravital two-photon microscopy. ACS Nano 12, 7936-7945. doi: 10.1021/acsnano.8b02452

Qian, J., Zhu, Z., Leung, C. W., Xi, W., Su, L., Chen, G., et al. (2015). Long-term two-photon neuroimaging with a photostable AIE luminogen. Biomed. Opt. Express 6, 1477-1486. doi: 10.1364/BOE.6.001477

Qin, W., Alifu, N., Lam, J. W. Y., Cui, Y., Su, H., Liang, G., et al. (2020). Facile synthesis of efficient luminogens with AIE features for three-photon fluorescence imaging of the brain through the intact skull. Adv. Mater. 32:2000364. doi: 10.1002/adma.202000364

Qin, W., Zhang, P., Li, H., Lam, J. W. Y., Cai, Y., Kwok, R. T. K., et al. (2018). Ultrabright red AIEgens for two-photon vascular imaging with high resolution and deep penetration. Chem. Sci. 9, 2705-2710. doi: 10.1039/C7SC04820C

Ren, F., Shi, J., Tong, B., Cai, Z., and Dong, Y. (2019). Effects of fused rings linked to the 2,5-position of pyrrole derivatives with near-infrared emission on their aggregation-enhanced emission properties. Mater. Chem. Front. 3, 2072-2076. doi: 10.1039/C9QM00372J

Sasaki, S., Suzuki, S., Sameera, W. M. C., Igawa, K., Morokuma, K., and Konishi, G.-I. (2016). Highly twisted N,N-dialkylamines as a design strategy to tune simple aromatic hydrocarbons as steric environment-sensitive fluorophores. J. Am. Chem. Soc. 138, 8194-8206. doi: 10.1021/jacs.6b03749

Shimizu, M., Takeda, Y., Higashi, M., and Hiyama, T. (2009). 1,4-Bis(alkenyl)2,5-dipiperidinobenzenes: minimal fluorophores exhibiting highly efficient emission in the solid state. Angew. Chem. Int. Ed. 48, 3653-3656. doi: 10.1002/anie.200900963

Shustova, N. B., Cozzolino, A. F., Reineke, S., Baldo, M., and Dincă, M. (2013). Selective turn-on ammonia sensing enabled by high-temperature fluorescence in metal-organic frameworks with open metal sites. J. Am. Chem. Soc. 135, 13326-13329. doi: 10.1021/ja407778a

Song, Y., Zhang, X., Shen, Z., Yang, W., Wei, J., Li, S., et al. (2020). Improving brightness and stability of si-rhodamine for super-resolution imaging of mitochondria in living cells. Anal. Chem. 92, 12137-12144. doi: 10.1021/acs.analchem.9b04926

Tadayon, M. A., Chaitanya, S., Martyniuk, K. M., Mcgowan, J. C., Roberts, S. P., Denny, C. A., et al. (2019). 3D microphotonic probe for high resolution deep tissue imaging. Opt. Express 27, 22352-22362. doi: 10.1364/OE.27.022352

Tozer, G. M., Kanthou, C., and Baguley, B. C. (2005). Disrupting tumour blood vessels. Nat. Rev. Cancer 5, 423-435. doi: 10.1038/nrc1628

Tsujimoto, H., Ha, D.-G., Markopoulos, G., Chae, H. S., Baldo, M. A., and Swager, T. M. (2017). Thermally activated delayed fluorescence and aggregation induced emission with through-space charge transfer. J. Am. Chem. Soc. 139, 4894-4900. doi: 10.1021/jacs.7b00873

Tu, Y., Zhao, Z., Lam, J. W. Y., and Tang, B. Z. (2020). Mechanistic connotations of restriction of intramolecular motions (RIM). Nat. Sci. Rev. nwaa260. doi: $10.1093 /$ nsr/nwaa260

Wang, L., Chen, X., Xiong, W., Ran, X., Tang, H., and Cao, D. (2020). Design and synthesis of an AIEgen with multiple functions: Solvatochromism, chromism, lipid droplet imaging. Dyes Pigm. 181:108537. doi: 10.1016/j.dyepig.2020.108537

Wang, S., Hu, F., Pan, Y., Ng, L. G., and Liu, B. (2019a). Bright AIEgenprotein hybrid nanocomposite for deep and high-resolution in vivo twophoton brain imaging. Adv. Funct. Mater. 29:1902717. doi: 10.1002/adfm.20190 2717
Wang, S., Liu, J., Goh, C. C., Ng, L. G., and Liu, B. (2019b). NIR-II-excited intravital two-photon microscopy distinguishes deep cerebral and tumor vasculatures with an ultrabright NIR-I AIE luminogen. Adv. Mater. 31:1904447. doi: 10.1002/adma.201904447

Wang, Y., Hu, R., Xi, W., Cai, F., Wang, S., Zhu, Z., et al. (2015). Red emissive AIE nanodots with high two-photon absorption efficiency at $1040 \mathrm{~nm}$ for deep-tissue in vivo imaging. Biomed. Opt. Express 6, 3783-3794. doi: 10.1364/BOE.6.003783

Wang, J., Huo, F., Yue, Y., and Yin, C. (2020). A review: Red/near-infrared (NIR) fluorescent probes based on nucleophilic reactions of $\mathrm{H}_{2} \mathrm{~S}$ since 2015. Luminescence. doi: 10.1002/bio.3831. [Epub ahead of print].

Wei, H., Zeng, R., Wang, S., Zhang, C.-H., Chen, S., Zhang, P., et al. (2020). Engineering of a zero cross-talk fluorescent polymer nanoprobe for selfreferenced ratiometric imaging of lysosomal hypochlorous acid in living cells. Mater. Chem. Front. 4, 862-868. doi: 10.1039/C9QM00733D

Wu, W., and Li, Z. (2020). Nanoprobes with aggregation-induced emission for theranostics. Mater. Chem. Front. doi: 10.1039/D0QM00617C

Xiang, J., Cai, X., Lou, X., Feng, G., Min, X., Luo, W., et al. (2015). Biocompatible green and red fluorescent organic dots with remarkably large two-photon action cross sections for Targeted cellular imaging and real-time intravital blood vascular visualization. ACS Appl. Mater. Interfaces 7, 14965-14974. doi: 10.1021 /acsami.5b03766

Xie, S., Wong, A. Y. H., Chen, S., and Tang, B. Z. (2019). Fluorogenic detection and characterization of proteins by aggregation-induced emission methods. Chem. Eur. J. 25, 5824-5847. doi: 10.1002/chem.201805297

Xu, J., Zhang, H., Zhang, W., Li, P., Zhang, W., Wang, H., et al. (2020). Fluorescent nanosensor for in situ detection of phosphate and alkaline phosphatase in mice with parathyroid dysfunction. Chem. Commun. 56, 2431-2434. doi: 10.1039/C9CC08828H

Xu, Y., Li, C., Xu, R., Zhang, N., Wang, Z., Jing, X., et al. (2020). Tuning molecular aggregation to achieve highly bright AIE dots for NIR-II fluorescence imaging and NIR-I photoacoustic imaging. Chem. Sci. 11, 8157-8166. doi: 10.1039/D0SC03160G

Yan, X., Remond, M., Zheng, Z., Hoibian, E., Soulage, C., Chambert, S., et al. (2018). General and scalable approach to bright, stable, and functional AIE fluorogen colloidal nanocrystals for in vivo imaging. ACS Appl. Mater. Interfaces 10, 25154-25165. doi: 10.1021/acsami.8b07859

Yan, X., Wang, H., Hauke, C. E., Cook, T. R., Wang, M., Saha, M. L., et al. (2015). A suite of tetraphenylethylene-based discrete organoplatinum(II) metallacycles: controllable structure and stoichiometry, aggregation-induced emission, and nitroaromatics sensing. J. Am. Chem. Soc. 137, 15276-15286. doi: $10.1021 /$ jacs.5b10130

Yang, J., Gao, Y., Jiang, T., Liu, W., Liu, C., Lu, N., et al. (2017). Substituent effects on the aggregation-induced emission and two-photon absorption properties of triphenylamine-dibenzo[a,c]phenazine adducts. Mater. Chem. Front. 1, 1396-1405. doi: 10.1039/C7QM00024C

Ye, M., Hu, W., He, M., Li, C., Zhai, S., Liu, Z., et al. (2020). Deep imaging for visualizing nitric oxide in lipid droplets: discovering the relationship between nitric oxide and resistance to cancer chemotherapy drugs. Chem. Commun. 56, 6233-6236. doi: 10.1039/D0CC01856B

Yin, W., Li, Y., Li, N., Yang, W., An, H., Gao, J., et al. (2020). Hybridization of triphenylamine and salicylaldehyde: a facile strategy to construct aggregationinduced emission luminogens with excited-state intramolecular proton transfer for specific lipid droplets and gram-positive bacteria imaging. Adv. Opt. Mater. 8:1902027. doi: 10.1002/adom.201902027

Zhang, D., Du, W., Peng, B., Ni, Y., Fang, H., Qiu, X., et al. (2020). Twophoton small molecular fluorogenic probe visualizing biothiols and sulfides in living cells, mice brain slices and zebrafish. Sens. Actuat. B-Chem. 323:128673. doi: 10.1016/j.snb.2020.128673

Zhang, F., Liu, Y., Yang, B., Wen, G., and Liu, B. (2020). Near-infrared AIEgens for lipid droplets imaging in corpus adiposum or trachea of Locusta migratoria and its application in photodynamic therapy. Sens. Actuat. B-Chem. 322:128589. doi: $10.1016 /$ j.snb.2020.128589

Zhang, J., Gao, L., Zhang, Z., Zhou, W., Gao, T., Zhai, L., et al. (2020). A highly selective luminescent logic gates probe based on Cd-LMOF for $\mathrm{pH}$ detection. Microp. Mesop. Mater. 305:110368. doi: 10.1016/j.micromeso.2020.110368

Zhang, M., Yin, S., Zhang, J., Zhou, Z., Saha, M. L., Lu, C., et al. (2017). Metallacycle-cored supramolecular assemblies with tunable fluorescence 
including white-light emission. Proc. Natl. Acad. Sci. U.S.A. 114, 3044-3049. doi: 10.1073/pnas.1702510114

Zhang, M.-M., Ma, Y.-H., Li, P., Jia, Y., and Han, K.-L. (2020). Detection of atherosclerosis-related hypochlorous acid produced in foam cells with a localized endoplasmic reticulum probe. Chem. Commun. 56, 2610-2613. doi: 10.1039/D0CC00090F

Zhang, Q., Zhang, P., Gong, Y., and Ding, C. (2019). Two-photon AIE based fluorescent probe with large stokes shift for selective and sensitive detection and visualization of hypochlorite. Sens. Actuat. B-Chem. 278, 73-81. doi: 10.1016/j.snb.2018.09.057

Zhang, R., Niu, G., Lu, Q., Huang, X., Chau, J. H. C., Kwok, R. T. K., et al. (2020). Cancer cell discrimination and dynamic viability monitoring through wash-free bioimaging using AIEgens. Chem. Sci. 11, 7676-7684. doi: 10.1039/D0SC01213K

Zhang, W., Kang, J., Li, P., Wang, H., and Tang, B. (2015). Dual signaling molecule sensor for rapid detection of hydrogen sulfide based on modified tetraphenylethylene. Anal. Chem. 87, 8964-8969. doi: 10.1021/acs.analchem.5b02169

Zhang, X., Yuan, L., Jiang, J., Hu, J., Du Rietz, A., Cao, H., et al. (2020). Light-up lipid droplets dynamic behaviors using a red-emitting fluorogenic probe. Anal. Chem. 92, 3613-3619. doi: 10.1021/acs.analchem.9b04410

Zhang, Y., Wang, Y., Wang, J., and Liang, X.-J. (2018). Improved pharmaceutical research and development with AIE-based nanostructures. Mater. Horiz. 5, 799-812. doi: 10.1039/C8MH00648B

Zhao, N., Li, Y., Yang, W., Zhuang, J., Li, Y., and Li, N. (2019). Multifunctional pyrazoline based AIEgens: real-time tracking and specific protein "fishing" of lipid droplets. Chem. Sci. 10, 9009-9016. doi: 10.1039/C9SC03111A

Zhao, Y., Li, H., Chai, Z., Shi, W., Li, X., and Ma, H. (2020). An endoplasmic reticulum-targeting fluorescent probe for imaging $(\mathrm{OH})-\mathrm{O}$-center dot in living cells. Chem. Commun. 56, 6344-6347. doi: 10.1039/D0CC00233J

Zheng, Z., Li, D., Liu, Z., Peng, H.-Q., Sung, H. H. Y., Kwok, R. T. K., et al. (2019). Aggregation-induced nonlinear optical effects of aiegen nanocrystals for ultradeep in vivo bioimaging. Adv. Mater. 31:1904799. doi: 10.1002/adma.201904799

Zheng, Z., Liu, H. X., Zhai, S. D., Zhang, H. K., Shan, G. G., Kwok, R. T. K., et al. (2020). Highly efficient singlet oxygen generation, two-photon photodynamic therapy and melanoma ablation by rationally designed mitochondria-specific near-infrared AIEgens. Chem. Sci. 11, 2494-2503. doi: 10.1039/C9SC06 $441 \mathrm{~A}$

Zheng, Z., Zhang, T., Liu, H., Chen, Y., Kwok, R. T. K., Ma, C., et al. (2018). Bright near-infrared aggregation-induced emission luminogens with strong twophoton absorption, excellent organelle specificity, and efficient photodynamic therapy potential. ACS Nano 12, 8145-8159. doi: 10.1021/acsnano.8b03138

Zhi, X., Shen, B., and Qian, Y. (2020). A novel carbazolyl GFP chromophore analogue: synthesis strategy and acidic $\mathrm{pH}$-activatable lysosomal probe for tracing endogenous viscosity changes. New. J. Chem. 44, 8823-8832. doi: 10.1039/D0NJ01477J

Zhong, X., Yang, Q., Chen, Y., Jiang, Y., and Dai, Z. (2020). Aggregation-induced fluorescence probe for hypochlorite imaging in mitochondria of living cells and zebrafish. J. Mater. Chem. B 8, 7375-7381. doi: 10.1039/D0TB01496F

Zhou, Y., Hua, J., Tang, B. Z., and Tang, Y. (2019). AIEgens in cellbased multiplex fluorescence imaging. Sci. China Chem. 62, 1312-1332. doi: 10.1007/s11426-019-9508-6

Zhu, Z., Leung, C. W. T., Zhao, X., Wang, Y., Qian, J., Tang, B. Z., et al. (2015). Using AIE luminogen for longterm and low-background three-photon microscopic functional bioimaging. Sci. Rep. 5:15189. doi: 10.1038/srep1 5189

Zou, Z., Luo, Z., Xu, X., Yang, S., Qing, Z., Liu, J., et al. (2020). Photoactivatable fluorescent probes for spatiotemporal-controlled biosensing and imaging. TrAC Trend. Anal. Chem. 125:115811. doi: 10.1016/j.trac.2020.11 5811

Conflict of Interest: The authors declare that the research was conducted in the absence of any commercial or financial relationships that could be construed as a potential conflict of interest.

Copyright (C) $2020 \mathrm{Lu}, \mathrm{Wu}, \mathrm{Liu}, \mathrm{Niu}$ and $\mathrm{Yu}$. This is an open-access article distributed under the terms of the Creative Commons Attribution License (CC BY). The use, distribution or reproduction in other forums is permitted, provided the original author(s) and the copyright owner(s) are credited and that the original publication in this journal is cited, in accordance with accepted academic practice. No use, distribution or reproduction is permitted which does not comply with these terms. 